\title{
Music from the kitchen
}

\author{
Charles Spence $^{1,2}$
}

\begin{abstract}
A growing body of scientific research has recently started to demonstrate how both music and soundscapes can influence people's perception of the taste, flavour, and mouthfeel of food and drink. However, to date, far less research has investigated the question of whether the music that happens to be playing in the background might also influence the way in which chefs, home cooks, and others making food (or, for that matter, mixing drinks) develop or season their creations. One of the aims of this review is to highlight the markedly different views currently held by chefs concerning the appropriateness of music in their kitchens (and the different roles that it might play). Next, the evidence that has been published to date suggesting that the music people listen to can change the particular taste/flavour profiles that they create is reviewed. A number of putative explanations for the crossmodal effects of music on taste are evaluated, including the suppressive effect of loud noise on certain aspects of taste perception, priming through crossmodal correspondences, and/or the influence of any music-induced changes in mood on taste/flavour perception. Given that what we hear influences what we taste, and hence, how the person in the kitchen likely creates/seasons the dish, some commentators have been tempted to wonder whether the same music should perhaps also be played in the spaces (e.g., the restaurant or home dining room) where that food will be consumed in order to equate the conditions in which the dish or drink is seasoned/created with the environment in which it is tasted. This opinion piece ends by stressing the limitations with such an approach. One of the main problems being the kinds of music that the majority of chefs apparently prefer to listen to while working in the kitchen, music which is often chosen to motivate the staff who will likely be working a long shift.
\end{abstract}

Keywords: Music, Taste, Flavour, Culinary creation, Seasoning, Crossmodal correspondence

\section{Introduction}

Music from the kitchen

Unlike the sentiment captured in an ad of a few years ago from AEG Electrolux for its kitchen appliances that had the strapline "The kitchen that sounds like a library.", kitchens, especially busy commercial kitchens, are places that are full of noise-or at least they should be. As chef Zakary Pelaccio, founder of the Fatty Crab and Fatty 'Cue restaurants in North America, puts it in his book "Eat with your hands", "Instead of a silent kitchen, with all the vitality of a courtroom, you want a kitchen that's a party. So turn on some music"..."Every professional kitchen I have ever run and every home kitchen I have ever spent time in has been filled with music. If you watch closely, you'll notice that everyone's cooking to the beat. Good cooks all have a natural

\footnotetext{
Correspondence: charles.spence@psy.ox.ac.uk

${ }^{1}$ Crossmodal Research Laboratory, Oxford University, Oxford, UK

${ }^{2}$ Department of Experimental Psychology, University of Oxford, Oxford OX1
} 3UD, UK

\section{() Biomed Central}

groove to begin with-you can see it in their step, hear it in the way they chop or in the pound of their pestle. That groove is the subtle manifestation of a cook's connection with his ingredients. So turn the music up." ([28], p. 14). ${ }^{1}$

All of the recipes in Pelaccio's [28] book come with a musical recommendation concerning what to listen to while preparing the dish. So, for anyone thinking about cooking, the chef's Frog leg clay pot, for example, the musical suggestion is "Ghostland Observatory, or any other cheesy, fun dance music, will keep you on your toes so you don't overcook the croaker. As you listen, hop around a bit in homage." ([28], p. 19). ${ }^{2}$

In a sense following up on Pelaccio's [28] suggestion, Sweden's Per Samuelsson literally makes music with the sounds from the kitchen. He records the sounds of preparation, the noise of peeling, chopping, slicing, dicing, grinding, shaking, and stirring as the chefs work to prepare the dishes that will later be served (see Fig. 1). ${ }^{3}$ These sounds are then used as the elements (or 


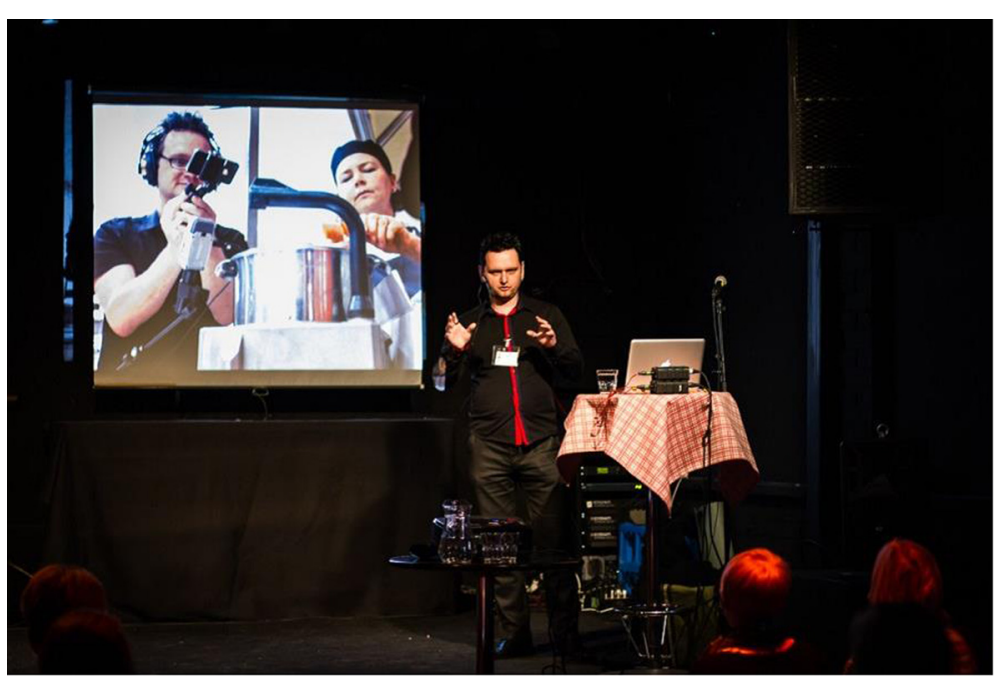

Fig. 1 Per Samuelsson on stage at the 2014 Sensibus Festival in Finland. The projection in the background shows the musician making the initial recordings in the kitchen for one of his performances

instruments if you will) in his musical compositions. A key element of these performances is that they are very much site/event specific. That is, the musical compositions are played back to the diners while they are tucking into the fruits of the chef's labours. They literally hear the food being made. It is easy to imagine how such an approach might help foster a closer connection between the kitchen and the diners. Indeed, it would certainly be intriguing to conduct the appropriate experimental research to assess this claim empirically. According to Samuelsson [34], one of the aims behind his compositions is to highlight the often under acknowledged effort that is involved in creating the food that the diner all too happily eats. At the same time, Samuelsson hopes to create an immersive multisensory environment that enhances the experience of the meal for those who are lucky enough to be dining.

\section{Silence in the kitchen}

In stark contrast to Pelaccio's [28] professed preferred sonic accompaniment whenever he is cooking, you would not have heard any music had you been lucky enough to stumble into the kitchen of the ElBulli restaurant near Rosales, Spain. It was forbidden! In fact, just before the restaurant closed its doors for the last time, the great chef Ferran Adrià was quoted as saying "We never listen to music in the kitchen-we can't" [24]. Silence was also the order of the day in Chicago's famous Alinea restaurant (note that this restaurant is frequently ranked amongst the world's best). According to head chef Grant Achatz "There is no music in the restaurant at all...And no music in the kitchen." [12]. The reason being that Achatz did not want anything to interfere with the cooking (not to mention the diner's savouring of each and every bite of the food that he and his team prepared). Other famous restaurants with music-free kitchens include New York City's Eleven Madison Park. According to the chef, Daniel Humm "The kitchen has its own music. Based on the sound in the kitchen, you can tell how things are going. Music would interrupt that." [12].

\section{Music in the kitchen}

There is, though, another school of thought as to whether music should be played in the kitchen. Pelaccio is certainly not the only chef who believes that music is a good idea. According to one young chef at Recette, in New York's West Village, for example, music helps the creative juices to flow. ${ }^{4}$ As the chef there puts it "When it gets too hectic and overwhelming, I just turn on a tune. And I focus." [12]. So perhaps rather than thinking of music in the kitchen as a distraction, one should consider the important role that it can play in terms of motivating the staff who are working there [2], not to mention in facilitating the creative process. Indeed, there is a fairly extensive literature documenting the role of music in encouraging creativity (e.g., $[3,11,45]$ ).

According to one journalist who researched the topic, Recette is not unique in encouraging music in the kitchens: “'Ask around, and you'll hear a spate of testimonials like that. Many chefs in New York and across the country, especially those who are younger than 40 , depend on music as such a pivotal part of their creative process that they would feel adrift in the kitchen without it."..."I would kill myself," said chef Emma Hearst, 25, who could be found with her team, one evening in March, cranking Led Zeppelin's "Custard Pie" by the stove at Sorella, on the Lower East Side. "I wouldn't want to work with someone who didn't play music. I just wouldn't be happy... Music is the secret ingredient (on full blast) at Recette, and it's not the sort you would automatically associate 
with a delicate presentation of, say, roasted foie gras or blue prawn crudo. At this urbane bistro, those elegant dishes ride out of the kitchen on the percussive thunderclouds of Pearl Jam, Nine Inch Nails, Alice in Chains, Metallica and Tool."' [12]. More recently, other journalists have started to provide lists of the preferred music playing in the kitchens of restaurants stretching all the way from Dallas [23] to Washington D.C. [1].

\section{Motivational music}

The young Franco-Colombian chef, Charles Michel, currently the Chef in Residence at Oxford University's Crossmodal Research Laboratory describes Frank Cerutti, chef de cuisine at "le Louis XV" restaurant in Monaco's Hotel de Paris (http://en.wikipedia.org/wiki/Le_Louis_XV_(restaurant)), putting on heavy metal during the "mise en place" in order to make the kitchen staff go faster! Indeed, this anecdote hints at the part of the reasoning behind the chef's decision to deliver music being that it will hopefully motivate the workers. As Colin Lynch, the executive chef of Barbara Lynch Gruppo, comprising restaurants such as Menton and No. 9 Park, puts it "I don't think I've ever worked in a kitchen that didn't have some form of music in it. The whole energy of the kitchen changes. The speed at which people work changes depending what we listen to. During prep, you zone out. You're doing one thing for 45 minutes straight. It helps you keep that rhythm" [10].

\section{Musical seasoning: assessing the evidence}

Now, the question that one has to ask at this point is whether the music being listened to by all those chefs working the long shifts in the kitchen might not exert some influence on the way in which they end up preparing/seasoning the food. One early study that collected evidence that is in some way relevant to this question comes from Ferber and Cabanac ([9], Experiment 2). These researchers had a group of 10 men mix together either a pair of sweet solutions (one weak, the other strong) in order to obtain the most pleasant-tasting mixture of the two. They also had their participants mix together two salty solutions in order to make the least unpleasant-tasting solution. While mixing the solutions, and for the $20 \mathrm{~min}$ beforehand, these experimenters exposed their participants to one of four background noise conditions: unpleasant white noise presented at 70 or $90 \mathrm{~dB}$, the participant's own preferred pleasant music selection (at $90 \mathrm{~dB}$ ), or silence. Interestingly, however, no difference in people's preferred taste for the solutions was found as a function of the presence versus absence of noise when the drinks were analysed. Contrary to what might have been expected, given some of the opinions quoted so far in this paper, the atmospheric sound did not exert any effect on the composition of the drinks that were made, at least not in this early study. That said, one might wonder whether the solutions were complex enough to really allow the music to exert its full effect. ${ }^{5}$ Certainly, anything served in a home kitchen or restaurant setting is likely to be much more complex in terms of the tastes, textures, aromas, and flavours that are all competing for the diner's limited attention. The reason why complexity matters here is that any effects of selective attention may have more chance of affecting perception under those (complex) conditions where there are a number of elements of the flavour experience that the participant's attention can be drawn to. If one takes the contrast case of, say, a solution that has no taste/flavour other than sweetness, it may be difficult to draw the participant's attention away from that dominant taste.

Recently, a group of Finnish and Argentinian researchers arrived at a rather different conclusion with regard to the impact of music on taste composition [18]. These researchers had four groups of people, made up from the general public who happened to turn up to a public science fair, listen to music. The key manipulation was that the music had been pre-selected to have either a "sweet" or "sour" musical connotation (see Table 1). ${ }^{6}$ As an initial sanity check, the food/taste word associations that came to people's mind on listening to the music were assessed first. ${ }^{7}$ As expected, analysis of the data revealed that the associations were indeed connected to the putative taste of the music.

The participants in Kontukoski et al.'s [18] study were provided with a range of sweet and sour ingredients to play with and were invited to mix a drink that, in some sense, matched the music that they were listening to. The sweet ingredients included mango juice, orange juice, and liquid honey, while the sour juices included grapefruit, lemon, and pineapple. Analysis of the

Table 1 The four music tracks that were used in Kontukoski et al.'s [18] recent study. Listening to these pieces, some idiosyncrasies associated with the performances should perhaps be mentioned. First, the breathing of the pianist is clearly audible in the Satie piece. The Schumann recording is not of the highest quality. There is audience noise, and the recording itself is rather sharp sounding, and this aspect of the recording could possibly have affected the results reported by Kontukoski and colleagues

\section{Sweet music}

Trois Gymnopédies, No.2 Lent et triste by Erik Satie, composed in 1888, piano music (http://www.youtube.com/watch?v = 1loSL7CjE_w);

Davidsbündlertänze, Op. 6 No. 18, Nicht schnell, C major, Eusebius by Robert Schumann composed in 1837, piano music (http:// www.youtube.com/watch? $v=j l H s N I w D 6 j Q) ;$

Sour music

Superscriptio by Brian Ferneyhough, composed in 1981, flute music (http://www.youtube.com/watch?v=dYnYimo8z2Q);

Fragments of transformed Argentinian tangos by Bruno Mesz (2012) 
composition of the drinks at the end of the study revealed that significantly sweeter drinks had indeed been mixed (123 g/l of sugar and $8.6 \mathrm{~g} / \mathrm{l}$ total acid content) while listening to the "sweeter" musical selections than while listening to the putatively sour music ( $97 \mathrm{~g} / \mathrm{l}$ of sugar and $11.9 \mathrm{~g} / \mathrm{l}$ total acid content). It is, though, perhaps interesting to pause for a moment here in order to think about how else these results might have turned out. A priori, one might have anticipated either an assimilation or a contrast effect (see [29, 35]). The "sweet" music might have been expected to prime the associated taste and hence result in the participants making drinks that were, on average, sweeter. Alternatively, however, the "sweet" music might have been expected to result in the participants adding less sweetness to their drink (since some sweetness was provided by the music playing in the background).

Kontukoski et al.'s [18] intriguing results fall some way short of demonstrating that the nature of the music that just so happens to be playing in the background in the restaurant (or, for that matter, home) kitchen will necessarily bias the nature of the dishes that are made, or at the very least, the seasoning that is applied. That said, these results most certainly do represent a step in the right direction when it comes to assessing such a claim empirically. It will, then, be an intriguing question for future research to determine what would happen if this particular study, or one quite like it, were to be repeated with a new group of participants. In this case, though, the participants would simply be instructed to mix a drink to their own preferred taste, while the background music was unobtrusively (and incidentally) changed between sweet and sour from one drink to the next or vice versa.

\section{On the crossmodal correspondence between music and taste}

Kontukoski et al.'s [18] results can be framed in terms of the growing literature highlighting the sometimessurprising crossmodal correspondences that exist in all of us between the music we hear and certain specific tastes, aromas, and flavours (e.g., $[6,14])$. What this means, in practice, is that by playing a certain piece of music, our attention can be biased in terms of the elements (i.e., tastes and/or flavours) that we concentrate on [7]. So, for example, play high pitched tinkling piano or wind chimes and people's attention will be drawn toward the sweeter tastes in a dish. By contrast, play lower pitched and/or brassy music and the bitter notes of e.g., dark chocolate or coffee will be accentuated (see $[5,43])$. However, while attention may be a necessary precondition for certain crossmodal correspondences to exert their effect, it would seem likely that other correspondences may operate in the absence of any explicit attention on the part of the participant to the component unisensory stimuli.

\section{Mood music}

Now it is, of course, important to bear in mind here that the taste of the music (i.e., whether it is "sweet" or "sour") is not the only way in which what we hear might be expected to influence how we prepare or season the food or drink. There is also the possibility that music can induce a certain mood or emotion in those who happen to be listening to it [17]. This, in turn, might be expected to influence taste perception, and hence, the way in which a chef seasons a dish [42]. So, for example, it has been shown that a person's mood can influence their ability to detect both olfactory (e.g., [31]) and gustatory stimuli (Heath et al., 2006; [39]). ${ }^{8}$ In one representative study, Pollatos et al. presented their participants with pleasant, unpleasant, and neutral pictures from the International Affective Picture System (IAPS) database. After having viewed a selection of the unpleasant pictures, the participants' sensitivity to olfactory stimuli was lowered, as a result of the negative emotional stimulation. Elsewhere it has been shown that those individuals who are anxious tend to be less sensitive to bitterness and to salty tastes (Heath et al., 2006; [39]). Normal individuals who are stressed, meanwhile, show increased sensitivity to the bitter taste of saccharin [8]. Emotion has also been shown to affect olfactory perception [4].

It would not seem like too much of a stretch to imagine that certain kinds of background music might put the chef (or whoever else happens to be in charge of preparing or seasoning the food) in a particular mood, either positive or negative. This, in turn, may be expected to subtly influence their taste/flavour perception, and hence, the way in which they end up seasoning a dish. Just such a suggestion was, in fact, captured some years ago by Salman Rushdie in his prize-winning novel "Midnight's Children" when the narrator says "..and Amina stirred her disappointments into a hot lime chutney which never failed to bring tears to the eyes." ([33], p. 172). Given that our mood affects our perception of the taste (and flavour) of food and drink, it would certainly be intriguing in future research to investigate whether listening to an uplifting versus to a depressing piece of music would really affect the way in which a chef seasons his/her food. Certainly, the suggestion from those eating in the restaurant itself is that if you get the music right the food just tastes better. Just take the following, “...I'm sitting in a restaurant-there's music. You know why they have music in restaurants? Because it changes the taste of everything. If you select the right kind of music, everything tastes good. Surely people who work in restaurants know this..." ([21], pp. 81-82). ${ }^{9}$

\section{Masking taste with loud noise}

Finally, here, in terms of the putative mechanism(s) underlying the crossmodal effect of music on taste, it is 
worth noting that loud sounds have been shown to suppress our ability to taste (see [41]). Here, think only of the loud noise (c. $85 \mathrm{~dB}$ ) of the engines on the airplane. Such loud background noise suppresses the ability of people to taste sweetness and saltiness, but counterintuitively enhances their ability to perceive the taste of umami ([46]; [47]). ${ }^{10}$ The problem of loud background noise is not restricted to the air, though. The noise levels in many popular restaurants are, in fact, much louder. With the noise in many restaurants (made up of both the background music and the noise of animated conversation) coming in at 90$100 \mathrm{~dB}$, it is no wonder that a growing number of restaurant critics now include noise ratings alongside the quality of the food (see [40], for a review).

It is, though, an open question as to whether this kind of restaurant noise would exert the same idiosyncratic effect on the perception of different tastes as the sound of aircraft engines has recently been shown to do. Crosssensory masking is, then, a likely third route by which what we hear changes what we taste and how much we end up enjoying the experience.

\section{Application}

Given what we have seen so far in this opinion piece, one could easily start to become convinced that the test kitchen in Splendid Ice Creams in Columbus Ohio might really be on to something: According to one journalist who visited the site, each room has a different sound, depending on the ice cream flavour that is currently being concocted. She continues, "If employees are languorously toasting marshmellows with a blowtorch, you may hear Schubert. If they're stirring ancient ingredients like frankincense and honey and almonds for one of the holiday flavors, the backdrop may be the somber, runic ballads of a Danish singer named Agnes Obel. Summery, cake-studded batches come to life to bright and shiny pop by the likes of Lady Gaga, Katy Perry, Madonna, and Nicki Minaj." [12].

Over-and-above any role that the music has in motivating one's staff to keep chopping, then, one has to wonder whether the chef in charge of the restaurant might not also want to match the music playing in the kitchen to the dishes/sauces that they happen to be preparing?

\section{Conclusions}

As this opinion piece has hopefully made clear, professional chefs hold very different views concerning the appropriateness of music in the kitchens they run. While some chefs cannot cook without it, others have banned it entirely from the kitchens they operate. That said, my sense from the literature is that music has become a more common feature of restaurant kitchens in recent years. Not in all of them, for sure, but certainly in a growing proportion. The evidence that has started to emerge now demonstrates that what we hear, be we a chef or home cook, can, at least in certain cases, influence the way in which we season the food. This might be as the result of the crossmodal correspondence between the sonic properties of the music and taste/flavour perception. Alternatively, however, it might also result from the potential mood-altering or emotion-inducing effect of music and the consequent effect of mood/emotion on taste/aroma perception. Finally, it is certainly important not to forget the suppressive effect of overly loud background noise on taste perception (what is referred to by some as crossmodal masking; see [40], for a review). Of course, over-andabove any effect that music has on the way the chef seasons the food, it is important not to neglect music's motivational role, its ability to alleviate boredom, and perhaps also its role in creative problem solving (e.g., $[11,45])$.

In closing, there may be those out there who may be wondering why we should care about what, if anything, the chefs play in the kitchen. Well, the evidence reviewed here certainly suggests the musical trends in the kitchen are increasingly making their way into the dining rooms of many a popular restaurant [40]. Furthermore, given that what we hear can influence what we taste, and hence, how the person in the kitchen creates/seasons the dish, one might be tempted to speculate about whether the same music should also be played in the spaces (e.g., the restaurant or home dining room) where that food will be consumed. This perhaps surprising suggestion was first captured by First [10] in a piece where it was stated that "Certainly, if the way the food tastes, and how much we like the experience really is influenced by the music that happens to be playing in the background then it might well make sense to adopt the strategy of playing exactly the same music in the kitchens as in the dining room."

However, that said, one should always remember that "No matter how elegant the food at a restaurant, the music that plays as it's prepared is likely to be less refined. No one is listening to Vivaldi as he buffs baby vegetables and dismembers ducks" [10]! Having said that, though, there are certainly some commentators out there who would be tempted to argue that whatever the music, it has to be better than the muzak that has been playing for too long in so many of the restaurants around the developed world $[16,22] .{ }^{11}$

\section{Endnotes}

${ }^{1}$ Though, there are many out there who believe that that is exactly where such music should stay (i.e., in the kitchen; e.g., see [30]; [40]).

${ }^{2}$ However, given that the chef starts his book with the following: "Not sure what beat will get the party started? Well, I've taken the liberty of suggesting the perfect music-recipe pairings. These suggestions are the result 
of rigorous experimenting and consultations with MIT sound scientists-actually, I just made them up. While I can't say with any certainty that listening to the suggested tunes enhances the flavour of a dish, I can tell you that you walk (and cook) taller when you have theme music." ([28], p. 14), perhaps we shouldn't take his musical choices as indicating anything more than merely personal preference.

${ }^{3}$ Samuelsson's approach is not to be confused with that of Linsey Pollak, an artist/performer who makes musical instruments out of vegetables (e.g., see http://www.linseypollak.com/).

${ }^{4}$ According to research by Mehta et al. [25], a moderate level of background noise (c. $70 \mathrm{~dB}$ ) can be conducive to problem solving (at least when compared to a $50 \mathrm{~dB}$ quiet condition).

${ }^{5}$ Though, here it has to be admitted that defining "complexity" when it comes to flavour is no simple matter. Immediately, one might think of chemical complexity [32]. However, it is important to note that there is no simple mapping between chemical complexity and perceived complexity ([36-37]; [38]). Here, in the text, I have in mind perceived complexity.

${ }^{6}$ Analysis of the musical selections showed that the sour pieces were both rougher and brighter than the sweet musical selections. Roughness here refers to the sensory dissonance in the music, whereas brightness refers to the proportion of high-frequency spectral energy in the piece (see also [15]).

${ }^{7}$ Note that in this between-participants study, each of the participants only heard one piece of music.

${ }^{8}$ Taking things even further, those individuals who suffer from a mood disorder, or else suffer from major depression, have been shown to find it harder to detect olfactory and gustatory stimuli. That is, their sensory thresholds actually increase (e.g., Heath et al., 2006; [20]; [27]; [45]).

${ }^{9}$ There is, of course, a danger of tautology here, in that what counts as "the right music" is defined by its having a positive impact on people's experience of the taste/flavour of the food.

${ }^{10}$ As to why background noise should have different effects on different tastes is not currently known. One possibility suggested by Yan and Dando [45] is that there may be some interference from the auditory nerves on those that transmit information about the taste of food and drink from mouth to brain.

${ }^{11}$ It should be noted here that while the term "muzak" is used in everyday language as a pejorative term for background music that the listener does not like, it is the more precise usage of the term that is being referred to here (see [19]).

\section{Competing interests}

The author declares that he has no competing interests.

\section{Acknowledgements}

CS would like to acknowledge the AHRC Rethinking the Senses grant (AH/L007053/1). Written informed consent was obtained for publication of this manuscript and accompanying images.

Received: 21 May 2015 Accepted: 30 June 2015

Published online: 15 July 2015

\section{References}

1. Anthony-Brown J. Sick beets: How D.C. chefs create their kitchen soundtracks. 2015. Downloaded from http://dcist.com/2015/03/ kitchen_music.php on 11/05/2015.

2. Baker T. Cooking to music: why chefs listen to heavy metal. The Guardian, 21st October. 2013. Downloaded from http://www.theguardian.com/ lifeandstyle/wordofmouth/2013/oct/21/cooking-music-chefs-heavy-metal on 12/05/2015.

3. Burns MT. Music as a tool for enhancing creativity. J Creat Behav. 1988;22:62-9.

4. Chen D, Dalton P. The effect of emotion and personality on olfactory perception. Chem Senses. 2005;30:345-51.

5. Crisinel A-S, Cosser S, King S, Jones R, Petrie J, Spence C. A bittersweet symphony: systematically modulating the taste of food by changing the sonic properties of the soundtrack playing in the background. Food Qual Prefer. 2012;24:201-4.

6. Crisinel A-S, Spence C. As bitter as a trombone: synesthetic correspondences in non-synesthetes between tastes and flavors and musical instruments and notes. Atten Percept Psychophys. 2010;72:1994-2002.

7. Deroy O, Crisinel A-S, Spence C. Crossmodal correspondences between odors and contingent features: odors, musical notes, and geometrical shapes. Psychon Bull Rev. 2013;20:878-96.

8. Dess NK, Edelheit D. The bitter with the sweet: the taste/stress/ temperament nexus. Biol Psychol. 1998;48:103-19.

9. Ferber $\mathrm{C}$, Cabanac M. Influence of noise on gustatory affective ratings and preference for sweet or salt. Appetite. 1987;8:229-35.

10. First $D$. Music to prep by: the tunes they name can lighten or quicken the mood before service. Boston Globe, July 27th. 2011. Downloaded from http://www.boston.com/ae/food/restaurants/articles/2011/07/27/ food_and_music_are_complements_in_most_kitchens__before_its_time_ to_focus_on_service/ on 12/05/2015.

11. Fitzpatrick F. Why music, Part 6: music and creativity. The Huffington Post, 20th February. 2013. Downloaded from http:/www.huffingtonpost.com/ frank-fitzpatrick/music-and-creativity_b_2253464.html on 27/06/2015.

12. Gordinier J. Who's rocking to the music? That's the chef. The New York Times, April 23rd. 2012. Downloaded from http://www.nytimes.com/2012/ 04/25/dining/when-the-music-moves-the-chef-and-themenu.html?pagewanted=all\&_r=0 on 27/07/2014.

13. Heath TP, Melichar JK, Nutt DJ, Donaldson LF. Human taste thresholds are modulated by serotonin and noradrenaline. J Neurosci. 2006;26:1266412671.

14. Knöferle KM, Spence C. Crossmodal correspondences between sounds and tastes. Psychon Bull Rev. 2012;19:992-1006.

15. Knöferle KM, Woods A, Käppler F, Spence C. That sounds sweet: using crossmodal correspondences to communicate gustatory attributes. Psychol Marketing. 2015;32:107-20.

16. Kogan P. Muzak-free London: a guide to eating, drinking ad shopping in peace. London, UK: Kogan Page; 1991.

17. Konečni VJ. Does music induce emotion? A theoretical and methodological analysis. Psychol Aesthetics Creativity Arts. 2008;2:115-29.

18. Kontukoski M, Luomala H, Mesz B, Sigman M, Trevisan M, Rotola-Pukkila M, et al. Sweet and sour: music and taste associations. Nutr Food Sci. 2015:45:357-76.

19. Lanza J. Elevator music: a surreal history of muzak, easy-listening, and other moodsong. Ann Arbor, Ml: University of Michigan Press; 2004.

20. Lombion-Pouthier S, Vandel P, Nezelof S, Haffen E, Millot JL. Odor perception in patients with mood disorders. J Affect Disord. 2006;90:187-91.

21. Luria AR. The mind of a mnemonist. Cambridge, MA: Harvard University Press; 1968.

22. Mariani J. How restaurant music got so bad: a brief history. Esquire, 13th August. 2013. Downloaded from http://www.esquire.com/blogs/food-formen/restaurant-music-history on 27/08/2014. 
23. McCarthy A. What Dallas chefs listen to while they cook. The Dallas Observer, March 25th. 2015. Downloaded from http:// blogs.dallasobserver.com/cityofate/2015/03/dallas_chefs_kitchen_music.php on $12 / 05 / 2015$.

24. McKnight R. Exit interview: Ferran Adrià. GQ Magazine, 7th July. 2011. Downloaded from http://www.gq.com/food-travel/restaurants-and-bars/ 201107/ferran-adria-exit-interview-el-bulli on 26/07/2014.

25. Mehta R, Zhu R, Cheema A. Is noise always bad? Exploring the effects of ambient noise on creative cognition. J Consum Res. 2012;39:784-99.

26. Mesz B, Sigman M, Trevisan MA. A composition algorithm based on crossmodal taste-music correspondences. FrontiHuman Neurosci. 2012;6:71, 1-6.

27. Pause BM, Miranda A, Goder R, Aldenhoff JB, Ferstl R. Reduced olfactory performance in patients with major depression. J Psychiatr Res. 2001;35:271-7.

28. Pelaccio Z. Eat with your hands. New York, NY: Ecco; 2012.

29. Piqueras-Fiszman B, Spence C. Sensory expectations based on productextrinsic food cues: an interdisciplinary review of the empirical evidence and theoretical accounts. Food Qual Prefer. 2015;40:165-79.

30. Platt A. Why restaurants are louder than ever. Grub Street New York. 2013. Retrieved July 16, 2013 [http://www.grubstreet.com/2013/07/adam-platt-onloud-restaurants.html].

31. Pollatos O, Kopietz R, Linn J, Albrecht J, Sakar V, Anzinger A, et al. Emotional stimulation alters olfactory sensitivity and odor judgment. Chem Senses. 2007;32:583-9.

32. Ruijschop RMAJ, Boelrijk AEM, Burgering MJM, de Graaf C, Westerterp-Plantenga MS. Acute effects of complexity in aroma composition on satiation and food intake. Chem Senses. 2010;35:91-100.

33. Rushdie S. Midnight's children. London, UK: Picador; 1982.

34. Samuelsson P. Taste of sound — composing for large scale dinners. Seinäjoki, Finland: Keynote presentation given at the Sensibus Festival; 2014. 13-14th March.

35. Schifferstein HNJ. Effects of product beliefs on product perception and liking. In: Frewer L, Risvik E, Schifferstein H, editors. Food, people and society: A European perspective of consumers' food choices. Berlin: Springer Verlag; 2001. p. 73-96.

36. Schlich P, Maraboli M, Urbano C, Parr W. Perceived complexity in Sauvignon blanc wines: Influence of domain-specific expertise. Aust J Grape Wine Res. 2015;21:168-78.

37. Singleton VL, Ough CS. Complexity of flavour and blending of wines. J Food Sci. 1962;27:189-96.

38. Smith B. Perspective: complexities of flavour. Nature. 2012;486:56.

39. Smith K. Mood makes food taste different. Nature, 6th December. 2006. Downloaded from http://www.nature.com/news/2006/061204/full/ news061204-5.html on 27/07/2015.

40. Spence $C$. Noise and its impact on the perception of food and drink. Flavour. 2014;3:9.

41. Spence C, Michel C, Smith B. Airplane noise and the taste of umami. Flavour. 2014;3:2

42. Spence C, Piqueras-Fiszman B. The perfect meal: the multisensory science of food and dining. Oxford, UK: Wiley-Blackwell; 2014.

43. Spence C, Richards L, Kjellin E, Huhnt A-M, Daskal V, Scheybeler A, et al. Looking for crossmodal correspondences between classical music \& fine wine. Flavour. 2013;2:29.

44. Steiner JE, Rosenthal-Zifroni A, Edelstein EL. Taste perception in depressive illness. Israel Annals Psychiat Related Discip. 1969;7:223-32.

45. Weinberger NM. Creating creativity with music. MusICA Research Notes, V(2). 1998. Downloaded from http://www.musica.uci.edu/mrn/ V512S98.html\#creating on 27/06/2015.

46. Woods AT, Poliakoff E, Lloyd DM, Kuenzel J, Hodson R, Gonda H, et al. Effect of background noise on food perception. Food Qual Prefer. 2011;22:42-7.

47. Yan KS \& Dando R. A crossmodal role for audition in taste perception. J Exp Psychol. in press 2015;41:590-596

\section{Submit your next manuscript to BioMed Central and take full advantage of:}

- Convenient online submission

- Thorough peer review

- No space constraints or color figure charges

- Immediate publication on acceptance

- Inclusion in PubMed, CAS, Scopus and Google Scholar

- Research which is freely available for redistribution

Submit your manuscript at www.biomedcentral.com/submit 